\title{
Handwriting Rehabilitation in Parkinson Disease: A Pilot Study
}

\author{
Adriana Ziliotto, PhD, Maria G. Cersosimo, MD, Federico E. Micheli, MD \\ Parkinson's Disease and Other Movement Disorders Unit, Hospital de Clinicas “Jose de San Martin”, \\ University of Buenos Aires, Argentina
}

Objective To assess the utility of handwriting rehabilitation (HR) in Parkinson disease (PD) patients who experienced difficulties with handwriting and signing.

Methods Sixty PD patients were prospectively studied with graphological evaluations. Thirty PD patients were assigned to HR for 9 weeks. At the end of this training, all patients were evaluated again and results of basal vs. final evaluations were compared.

Results At final evaluation, the group assigned to HR showed significantly larger amplitude of the first ' $\mathrm{e}$ ' in the phrase, larger signature surface area, and superior margin. A trend of increase in letter size was also observed. Handwriting with progressively decreasing size of letters and ascending direction with respect to the horizontal were prominent findings in both groups of patients and they did not change after HR.

Conclusion Rehabilitation programs for handwriting problems in PD patients are likely to be helpful. Larger randomized studies are needed to confirm these results.

Keywords Parkinson disease, Handwriting, Signature, Micrographia, Rehabilitation

\section{INTRODUCTION}

Handwriting impairment is commonly observed among Parkinson disease (PD) patients.

The term Micrographia means small letter size, and it has been widely used to globally describe handwriting disorders in PD patients [1-3]. However, the spectrum of

Received September 9, 2014; Accepted February 4, 2015

Corresponding author: Maria G. Cersosimo

Parkinson's Disease and Other Movement Disorders Unit, Hospital de Clinicas “Jose de San Martin", University of Buenos Aires, Cordoba 2351, Piso 9, Sala 1(C1120AAR) C.A.B.A., Argentina

Tel: +5411-5950-9021, Fax: +5411-4806-2217, E-mail: mgcersosimo@ gmail.com

(c) This is an open-access article distributed under the terms of the Creative Commons Attribution Non-Commercial License (http://creativecommons. org/licenses/by-nc/4.0) which permits unrestricted noncommercial use, distribution, and reproduction in any medium, provided the original work is properly cited.

Copyright $\odot 2015$ by Korean Academy of Rehabilitation Medicine handwriting abnormalities observed in PD is more complex than the mere reduction of letter size, and it comprises deficits that involve dysfunctions of other components such as force, velocity, or fluency of writing [3]. The exact prevalence of Micrographia in PD has not been clearly established in the literature, and it ranges from $9 \%$ to $75 \%$ according to different reports [4-6].

The underlying mechanism of handwriting impairment has not been fully elucidated but it appears to be unrelated to the striatal dopaminergic dysfunction that occurs in PD [7]. In fact, it has been reported that levodopa therapy has minimal or no effect on handwriting performance $[8,9]$. On the other hand, handwriting, similar to other automatic skills, such as walking or talking, can be improved by the effect of different external visual or auditory stimuli [10-12]. This is of interest as it provides the rationale for the use of non-pharmacological therapeutic 
strategies in the management of handwriting problems in PD patients.

We conducted a pilot study in order to assess the utility of handwriting rehabilitation (HR) in a group of PD patients who experienced difficulties with handwriting and signing.

\section{MATERIALS AND METHODS}

\section{Participants}

We studied 60 PD patients who were included in the Parkinson Disease and Movement Disorders Program in the Hospital de Clinicas "Jose de San Martin" at the University of Buenos Aires. The study was approved by the local Ethics Committee and written informed consent was obtained from all subjects. Inclusion criteria were diagnosis of idiopathic PD and difficulties with handwriting and signing. The diagnosis of PD was made according to the United Kingdom Brain Bank criteria [13]. The presence of handwriting problems was specifically assessed by a neurologist from the Parkinson Disease and Movement Disorders Program. Exclusion criteria included: Mini-Mental State Examination score $\leq 26$; severe dominant hand tremor or dyskinesia; history of other neurological diseases, such as peripheral neuropathies, stroke, or dystonia; osteoarticular diseases affecting the hand; and any other medical condition that could diminish the dominant hand skills. Hand tremor was considered to be severe when the score for items 20 and 21 of the Unified Parkinson's Disease Rating Scale (UPDRS) part-III was $\geq 2$ points. Dyskinesia affecting the dominant hand was considered to be severe when the score for item 33 of the UPDRS part-IV was $\geq 2$ points [14]. All patients were specifically asked not to make changes either in their pharmacological or non-pharmacological therapies during the study period.

\section{Study design}

The study design was prospective, longitudinal, and comparative. Duration of the study was 10 weeks, and all patients were evaluated at the beginning (basal evaluation) and at the end of the study (final evaluation). After the basal assessment, 30 PD patients were included in a HR program. The assignment of patients to this program was not randomized.

The group of patients assigned to HR participated in training sessions, once a week, for 9 weeks. After this period, both groups of PD patients (with and without HR) were evaluated and results between basal and final evaluations were compared.

\section{Assessments}

In order to analyze the graphological characteristics, participants were asked to write a phrase (in Spanish) "Respiro el dulce aroma de las flores" with their dominant hand on a blank, $40 \times 50 \mathrm{~cm}^{2}$, white sheet of paper. The following features were measured:

1) Letter size: characterized by vertical amplitude (highest vertical stroke of the phrase in millimeters) and width (phrase length in centimeters).

2) Decreasing size of letters: vertical amplitude (millimeters) of the first and the last ' $\mathrm{e}$ ' in the phrase.

3) Direction of handwriting (number of cases and percentage): ascending, horizontal, or descending (nominal variable) direction of handwriting with respect to the horizontal.

4) Surface area of the signature $\left(\mathrm{cm}^{2}\right)$ : was calculated by framing the signature within a quadrilateral with horizontal and vertical lines parallel to the sides of the sheet.

5) Superior margin (millimeters): distance from the highest vertical stroke of the phrase to the upper end of the sheet.

6) Force exerted was measured by employing the Calligraphy 2.7 software. This program classifies force from 1 (minimal) to 7 (maximal force), where 4 is considered normal.

7) Velocity or speed: number of letters written in one minute.

\section{Handwriting rehabilitation training}

HR training was conducted by a graphologist and each training session lasted 90 minutes.

The purpose of HR exercises was that the patient should be able to perform the handwriting task in a less automatic manner by using different external stimuli. Visual external stimuli were provided by asking the patients to write with multiple colored inks, and by using markers with broad nibs in order to produce thick strokes and spontaneous large letter size. Patients were asked to draw freely making large strokes across the whole area of the $40 \times 50 \mathrm{~cm}^{2}$ sheet of paper. Patients were also encouraged to include shoulder strength in the act of handwriting in 
order to minimize arm oscillations. Execution of calligrammes was part of the training and it was aimed at improving the control of writing direction. Auditory external cues consisted of rhythmic clapping of hands by the instructors and rhythmic music in the background during the training session.

\section{Statistical analysis}

Descriptive statistics were used to show the characteristics of the sample. Student t-test for paired samples was used to compare graphological changes before and after HR. The prevalence of the direction of writing (qualitative variable) at basal and final evaluations was compared using two by two tables and the chi-square test. A p-value $\leq 0.05$ was considered statistically significant. Statistical analyses were performed with the SPSS software ver. 20 (IBM SPSS, Armonk, NY, USA).

\section{RESULTS}

\section{Participants}

Sixty right-handed PD patients (33 females), with a mean age of $65.5 \pm 9.1$ years (range, 41 to 84 years) participated in this study. Forty-five cases showed the wearingoff phenomenon, and in these cases, all evaluations were performed during the 'On' motor condition. After the assignment of PD patients to the groups with $(n=30)$ and without HR $(n=30)$, socio-demographic characteristics were similar in both groups (Table 1).

\section{Basal evaluation}

The severity of handwriting impairment was similar in both groups for all the graphological variables assessed except for force, which was higher in the group not assigned to HR (Table 2). Most of the patients in the two groups exhibited handwriting with progressively decreasing size of letters and ascending direction with respect to the horizontal (Table 2).

Table 1. Demographic characteristics of the groups with and without HR

\begin{tabular}{lccc}
\hline & \multicolumn{3}{c}{ HR } \\
\cline { 2 - 4 } & Yes (n=30) & No $(\mathbf{n}=\mathbf{3 0})$ & p-value \\
\hline Age & $64.6 \pm 8.1$ & $66.5 \pm 10.2$ & 0.42 \\
Females & $14(46.7)$ & $19(63.3)$ & 0.29 \\
Education $(<8$ yr) & $11(36.7)$ & $15(50.0)$ & 0.21 \\
\hline
\end{tabular}

Values are presented as mean \pm standard deviation or number (\%).

HR, handwriting rehabilitation.

Table 2. Basal evaluation: comparison of graphological findings between the two groups

\begin{tabular}{|c|c|c|c|}
\hline \multirow{2}{*}{ Handwriting features } & \multicolumn{3}{|c|}{ HR } \\
\hline & Yes & No & p-value \\
\hline \multicolumn{4}{|l|}{ Letter size } \\
\hline Amplitude (mm) & $12.7 \pm 5.1$ & $13.0 \pm 4.9$ & NS \\
\hline Width $(\mathrm{cm})$ & $13.0 \pm 2.8$ & $13.8 \pm 2.7$ & NS \\
\hline \multicolumn{4}{|l|}{ Decreasing writing } \\
\hline First 'e' amplitude (mm) & $3.7 \pm 1.2$ & $3.8 \pm 1.2$ & NS \\
\hline Last 'e' amplitude (mm) & $3.5 \pm 1.4$ & $3.6 \pm 1.4$ & NS \\
\hline Signature surface area $\left(\mathrm{cm}^{2}\right)$ & $7.2 \pm 6.6$ & $9.0 \pm 6.2$ & NS \\
\hline Superior margin (mm) & $10.7 \pm 7.1$ & $8.8 \pm 6.9$ & NS \\
\hline \multicolumn{4}{|l|}{ Direction of writing } \\
\hline Horizontal & 0 & 0 & NS \\
\hline Ascending & $27(90.0)$ & $27(90.0)$ & NS \\
\hline Descending & $3(10.0)$ & $3(10.0)$ & NS \\
\hline Force (caligraph method) ${ }^{a)}$ & $5.3 \pm 1.7$ & $6.6 \pm 1.5$ & 0.004 \\
\hline Velocity (letters written per minute) & $83.0 \pm 28.1$ & $68.9 \pm 28.0$ & NS \\
\hline
\end{tabular}

Values are presented as mean \pm standard deviation or number (\%).

HR, handwriting rehabilitation; NS, not significant.

${ }^{a}$ See the Materials and Methods section. 


\section{Final evaluation}

The most relevant changes in the group that underwent HR were higher amplitude of the first ' $\mathrm{e}$ ' in the phrase, a larger signature surface area (Fig. 1), and a larger superior margin. There was a trend of increase in letter size (Fig. 2). Both the decreasing letter size and the ascending direction of handwriting did not change after HR. A significant increase in force was observed in the group not assigned to HR at final evaluation (Tables 3,4 ).

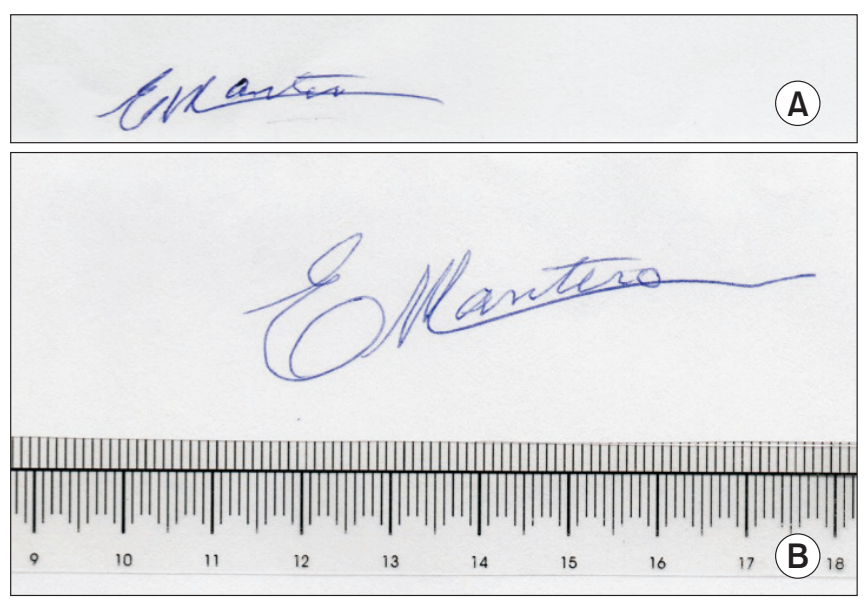

Fig. 1. The signature of a Parkinson disease patient before (A) and after (B) handwriting rehabilitation.

\section{DISCUSSION}

In this study, HR was associated with an improvement in most of the graphological variables assessed. These changes were significant for signature surface area, superior margin, and the amplitude of the first ' $\mathrm{e}$ ' in the phrase. Conversely, in the group without HR, a trend towards worsening of variables such as letter size, signature surface area, superior margin, and force was observed at the end of the study; however, these aggravations were only significant for force (Table 4).

Two prominent handwriting features observed in the group of PD patients were progressively decreasing size of letters and the ascending direction of the phrase with

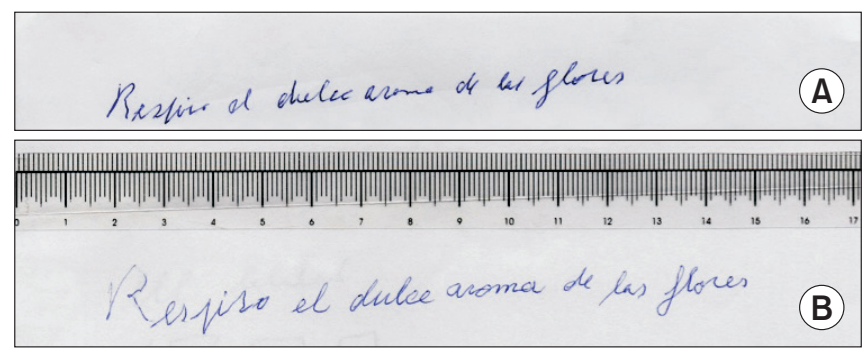

Fig. 2. A phrase written by a Parkinson disease patient before (A) and after (B) handwriting rehabilitation

Table 3. Final evaluation: comparison of graphological changes between the two groups

\begin{tabular}{|lccc}
\hline Handwriting features & & HR & \\
\cline { 2 - 3 } & Yes & No & p-value \\
\hline Letter size & & & \\
\hline Amplitude $(\mathrm{mm})$ & $13.9 \pm 5.7$ & $11.9 \pm 4.8$ & 0.02 \\
\hline Width (cm) & $13.8 \pm 2.9$ & $13.5 \pm 3.0$ & NS \\
\hline Decreasing writing & & & \\
\hline First 'e' amplitude (mm) & $4.2 \pm 1.1$ & $3.9 \pm 1.6$ & 0.01 \\
\hline Last 'e' amplitude (mm) & $3.8 \pm 1.5$ & $3.6 \pm 1.6$ & NS \\
\hline Signature surface area (cm $\left.{ }^{2}\right)$ & $11.9 \pm 10.6$ & $9.0 \pm 6.9$ & 0.02 \\
\hline Superior margin (mm) & $18.5 \pm 12.2$ & $8.3 \pm 6.4$ & 0.01 \\
\hline Direction of writing & & & \\
\hline Horizontal & $5(16.7)$ & $3(10.0)$ & NS \\
\hline Ascending & $25(83.3)$ & $24(80.0)$ & NS \\
\hline Descending & 0 & $3(10.0)$ & NS \\
\hline Force (caligraph method) ${ }^{\mathrm{a})}$ & $5.1 \pm 1.7$ & $7.2 \pm 1.6$ & 0.02 \\
\hline Velocity (letters written per minute) & $80.0 \pm 25.6$ & $66.7 \pm 32.0$ & NS \\
\hline
\end{tabular}

Values are presented as mean \pm standard deviation or number (\%).

HR, handwriting rehabilitation; NS, not significant.

${ }^{a}$ See the Materials and Methods section. 
Table 4. Graphological characteristics: comparison of basal vs. final findings in the two groups

\begin{tabular}{|c|c|c|c|c|c|c|}
\hline \multirow{2}{*}{ Handwriting features } & \multicolumn{3}{|c|}{ With HR $(n=30)$} & \multicolumn{3}{|c|}{ Without HR $(n=30)$} \\
\hline & Yes & No & p-value & Yes & No & p-value \\
\hline \multicolumn{7}{|l|}{ Letter size } \\
\hline Amplitude (mm) & $12.7 \pm 5.1$ & $13.9 \pm 5.7$ & 0.059 & $13.0 \pm 4.8$ & $11.9 \pm 4.8$ & 0.17 \\
\hline Width $(\mathrm{cm})$ & $13.0 \pm 2.8$ & $13.8 \pm 2.9$ & 0.23 & $13.8 \pm 2.7$ & $13.5 \pm 3.0$ & 0.46 \\
\hline \multicolumn{7}{|l|}{ Decreasing writing } \\
\hline First 'e' amplitude (mm) & $3.7 \pm 1.2$ & $4.2 \pm 1.1$ & 0.003 & $3.8 \pm 1.3$ & $3.9 \pm 1.6$ & 0.61 \\
\hline Last 'e' amplitude (mm) & $3.5 \pm 1.4$ & $3.8 \pm 1.5$ & 0.18 & $3.6 \pm 1.4$ & $3.6 \pm 1.6$ & 1.0 \\
\hline Signature surface area $\left(\mathrm{cm}^{2}\right)$ & $7.2 \pm 6.6$ & $11.9 \pm 10.6$ & 0.01 & $9.0 \pm 6.2$ & $9.0 \pm 6.9$ & 1.0 \\
\hline Superior margin $(\mathrm{mm})$ & $10.7 \pm 7.1$ & $18.5 \pm 12.2$ & 0.001 & $8.8 \pm 6.9$ & $8.3 \pm 6.4$ & 0.46 \\
\hline \multicolumn{7}{|l|}{ Direction of writing } \\
\hline Horizontal & 0 & $5(16.7)$ & 0.19 & 0 & $3(10.0)$ & 0.15 \\
\hline Ascending & $27(90.0)$ & $25(83.3)$ & 0.70 & $27(90.0)$ & $24(80.0)$ & 0.92 \\
\hline Descending & $3(10.0)$ & 0 & 0.19 & $3(10.0)$ & $3(10.0)$ & 0.97 \\
\hline Force (caligraph method) ${ }^{\text {a) }}$ & $5.3 \pm 1.7$ & $5.1 \pm 1.7$ & 0.45 & $6.6 \pm 1.5$ & $7.2 \pm 1.6$ & 0.02 \\
\hline Velocity (letters written per minute) & $83.0 \pm 28.1$ & $80.0 \pm 25.6$ & 0.22 & $68.9 \pm 28.0$ & $66.7 \pm 32.0$ & 0.34 \\
\hline
\end{tabular}

Values are presented as mean \pm standard deviation or number (\%).

HR, handwriting rehabilitation; NS, not significant.

${ }^{\text {a) }}$ See the Materials and Methods section.

respect to the horizontal. The decreasing size of letters among PD patients has been reported previously and it has been suggested that it might be helpful to distinguish PD from progressive supranuclear palsy (PSP) [7]. Patients with PSP typically show severe Micrographia but the progressive smaller amplitude of letters is not observed in these cases [7].

In PD, there is an impairment of some automatic skills, such as walking or handwriting [9]. The use of visual or auditory cues can help to make these tasks less automatic and thus achieve a better performance [10-12]. On this basis, previous studies have shown that an improvement in letter size can be achieved by encouraging patients to use larger font sizes by means of verbal reminders or visual stimuli $[9,10]$.

In this study, the improvement observed in PD patients who underwent HR probably indicates that these cases were capable of writing less automatically due to the use of external cues during rehabilitation exercises. The question whether these improvements would persist after the discontinuation of HR, and if so, for how long, should be further addressed.

Most previous studies focused on describing handwriting features in PD cases [11,15-17]; however, only a few of them used interventions for handwriting rehabilitation
$[5,10,12]$. The strengths of this study are that the graphological measurements were made by the same graphologist in all cases, there was a control group, and there were a relatively large number of PD patients.

The main limitations of this study are that the assignment of patients into the groups with and without HR was not randomized, and the severity of PD was not assessed by using standardized scales, such as the Hoehn and Yahr stage and the UPDRS. In this pilot study, we focused on assessing the severity of graphological findings at basal evaluation, which was similar in both groups, as shown in Table 2.

In summary, this preliminary study confirms previous observations $[10,12]$ regarding the beneficial effect of providing external cues in order to avoid automatic writing which is affected in PD. Given the fact that dopaminergic drugs have poor effect on improving handwriting $[8,9]$, the implementation of non-pharmacological therapeutic strategies should be considered in these cases. We suggest that HR may be helpful in improving handwriting difficulties among PD patients. If larger randomized studies confirm these results, HR should be included in the multidisciplinary approach necessary for PD management. 


\section{CONFLICT OF INTEREST}

No potential conflict of interest relevant to this article was reported.

\section{ACKNOWLEDGMENTS}

We thank Dr. Cristina Pecci for her work in the database preparation.

\section{REFERENCES}

1. Fahn S. Parkinson's disease: 10 years of progress, 1997-2007. Mov Disord 2010;25 Suppl 1:S2-14.

2. Lees AJ, Hardy J, Revesz T. Parkinson's disease. Lancet 2009;373:2055-66.

3. Letanneux A, Danna J, Velay JL, Viallet F, Pinto S. From micrographia to Parkinson's disease dysgraphia. Mov Disord 2014;29:1467-75.

4. Ishihara LS, Khaw KT, Luben R, Bingham S, Welch A, Day N, et al. Self-reported parkinsonian symptoms in the EPIC-Norfolk cohort. BMC Neurol 2005;5:15.

5. Jarzebska E. Evaluation of effectiveness of the micrographia's therapy in Parkinson's disease patients. Pol Merkur Lekarski 2006;20:688-90.

6. McLennan JE, Nakano K, Tyler HR, Schwab RS. Micrographia in Parkinson's disease. J Neurol Sci 1972;15: 141-52.

7. Ling H, Massey LA, Lees AJ, Brown P, Day BL. Hypokinesia without decrement distinguishes progressive supranuclear palsy from Parkinson's disease. Brain 2012;135(Pt 4):1141-53.

8. Kang SY, Wasaka T, Shamim EA, Auh S, Ueki Y, Lopez GJ, et al. Characteristics of the sequence effect in Parkinson's disease. Mov Disord 2010;25:2148-55.
9. Iansek R, Huxham F, McGinley J. The sequence effect and gait festination in Parkinson disease: contributors to freezing of gait? Mov Disord 2006;21:1419-24.

10. Oliveira RM, Gurd JM, Nixon P, Marshall JC, Passingham RE. Micrographia in Parkinson's disease: the effect of providing external cues. J Neurol Neurosurg Psychiatry 1997;63:429-33.

11. Kim EJ, Lee BH, Park KC, Lee WY, Na DL. Micrographia on free writing versus copying tasks in idiopathic Parkinson's disease. Parkinsonism Relat Disord 2005;11:57-63.

12. Bryant MS, Rintala DH, Lai EC, Protas EJ. An investigation of two interventions for micrographia in individuals with Parkinson's disease. Clin Rehabil 2010;24:1021-6.

13. Hughes AJ, Daniel SE, Kilford L, Lees AJ. Accuracy of clinical diagnosis of idiopathic Parkinson's disease: a clinico-pathological study of 100 cases. J Neurol Neurosurg Psychiatry 1992;55:181-4.

14. Fahn S, Elton RL; UPDRS Development Committee. Unified Parkinson's disease rating scale. In: Fahn S, Marsden CD, Calne DB, Goldstein M, editors. Recent developments in Parkinson's disease. Florham Park, NJ: Macmillan Health Care Information; 1987. p. 153-64.

15. Rosenblum S, Samuel M, Zlotnik S, Erikh I, Schlesinger I. Handwriting as an objective tool for Parkinson's disease diagnosis. J Neurol 2013;260:2357-61.

16. Wagle Shukla A, Ounpraseuth S, Okun MS, Gray V, Schwankhaus J, Metzer WS. Micrographia and related deficits in Parkinson's disease: a cross-sectional study. BMJ Open 2012;2:e000628.

17. Dounskaia N, Van Gemmert AW, Leis BC, Stelmach GE. Biased wrist and finger coordination in Parkinsonian patients during performance of graphical tasks. Neuropsychologia 2009;47:2504-14. 